Article

\title{
An IVTIFN-TOPSIS Based Computational Approach for Pipe Materials Selection
}

\author{
Rui Zhao ${ }^{1, *}$, Ya Huang ${ }^{1}$, Yang $\mathrm{Yu}^{1}$ and Sidai Guo ${ }^{2}$ \\ 1 Faculty of Geosciences and Environmental Engineering, Southwest Jiaotong University, Chengdu 611756, \\ China; YaHuang355@outlook.com (Y.H.); yuyang_hhu@163.com (Y.Y.) \\ 2 Sichuan Province Cyclic Economy Research Centre, Southwest University of Science and Technology, \\ Mianyang 621010, China; guosidai@126.com \\ * Correspondence: ruizhao@swjtu.edu.cn; Tel.: +86-28-6636-7628
}

Received: 15 November 2019; Accepted: 10 December 2019; Published: 12 December 2019

check for updates

\begin{abstract}
This paper proposes a multicriteria decision-making (MCDM) approach, coupling intervalued trapezoidal intuitionistic fuzzy number (IVTIFN) with the technique for order preference by similarity to ideal solution (TOPSIS) to facilitate the selection of pipe materials. Their integration can maximize the advantage in better expressing decision maker's preference on the proposed evaluation criteria by using a bounded limit instead of an exact value, to rank material alternatives based upon their functional, economic and environmental attributes. To reduce possible information overlapping resulted from the criteria, Mahalanobis distance is incorporated into IVTIFN-TOPSIS to improve the selection results. An illustrative example is provided to verify the proposed approach and demonstrate its practical application, in which four common alternative materials, including carbon steel, galvanized steel, polyvinyl chloride (PVC) and high-density polyethylenes (HDPE), are subject to precise selection to determine their adaptability in waste-water piping. The selection result indicates that the plastic materials are superior to the metal materials. In particular, HDPE is the optimal material alternative for waste-water collection and transport.
\end{abstract}

Keywords: materials selection; pipe material; multicriteria decision making; IVTIFN; TOPSIS; Mahalanobis distance

\section{Introduction}

Pipe materials are prone to chemical corrosion or scaling during waste-water collection and transportation, due to complex and harmful compounds contained. If the corrosion intensifies, it may cause failure of piping system, resulting in leakage and possible environmental damage [1]. Selection of appropriate materials is a premise to help with the careful design of a piping system, ultimately to ensure its operation in a safe and reliable way.

Material selection is crucial for engineering design [2]. It is a complex issue, in which a decision maker may encounter a number of conflicting or competing attributes, e.g., that the economic and functional performance of materials to some extent may not match each other [3]. Basically, the selection of materials is to meet the design requirements [4]. Mercer [5] presented that reliability and longevity was critical to selection of pipe materials, in which internal pressure and external loads were the primary criteria to assess their performances. Anojkumar et al. [6] further incorporated the mechanical properties with corrosion resistance into the selection criteria of pipe materials. Zhang et al. [7] took the compatibility of materials with the working fluid into the selection criteria of heating pipes. In addition to materials' functional performances, economic attributes are also important factors in influencing material selection to decrease the manufacturing cost [8,9]. Kayfeci [10] made a selection from five insulation materials based on their market price. Mendrinos et al. [11] evaluated the performance of 
pipe materials for a borehole heat exchanger (BHE) in terms of their installation costs. Zhao et al. [12] designed economic evaluation criteria for the selection of plastic pipes, including procurement cost, processing cost and market share. With the concept of environmentally conscious design emerging in lean manufacturing, material selection pays more attention to mitigation of the product's lifecycle environmental impact [13]. Du et al. [14] investigated the possible lifecycle impacts on different pipe materials to lead optimal selection. Akhtar et al. [15] selected the optimal pipe among four common sewage pipes based on their lifecycle environmental impacts.

The above-mentioned studies inform us of the key criteria that should be considered in pipe-materials selection, including functional, economic, and environmental aspects. However, they seldom surveyed the impact of correlation among different criteria that may give rise to information overlapping. Our study filled such a gap by using the correlation test to eliminate the most interrelated criteria, through which Mahalanobis distance is further coupled with the multicriteria decision-making (MCDM) method to reduce the uncertainty of the selection results.

Multicriteria decision making (MCDM) is classified into multiple-objective decision making (MODM) and multiple-attribute decision making (MADM) [16]. The former mainly focuses on applying optimization to satisfy predefined objective functions, whilst the latter ranks a finite number of alternatives according to their performances on a set of predetermined attributes [12,17]. Since multiple factors are being taken into decision analysis, MADM methods, including the Analytic Hierarchy Process (AHP), Elimination Choice Translating Reality (ELECTRE), the Preference-ranking Organization Method for Enrichment Evaluations (PROMETHEE), the Technique for Order Preference by Similarity to Ideal Solution (TOPSIS), Vise Kriterijumska Optimizacija I Kompromisno Resenje (VIKOR), Complex Proportional Assessment (COPRAS), etc., are widely employed to help decision makers carry out trade-offs among various alternatives. AHP has evolved into weighting the assignment of different criteria in a hierarchical indicator system [18], dealing with the inconsistency of group decision making [19], and examining the performance of Pareto-optimality on a set of feasible solutions [20]. ELECTREmay couple with AHP to rank alternatives depending upon their outranking relationships [21]. However, the methods fail to explain the information that lies in the differences of ranking scores [22]. PROMETHEE fills such gap by using different scores to indicate the degree of preference among alternatives [23]. AHP, ELECTRE and PROMETHEE are based upon pairwise comparison among attributes to rank alternatives, which is time consuming in computation, especially when the number of alternatives or attributes enlarges in the decision-making process [24,25]. TOPSIS, VIKOR and COPRAS are comparatively simple, systematic, and logical for decision makers to obtain the optimal option when facing a number of competing criteria [26]. TOPSIS and VIKOR are similar but different from their normalizations in selected indicators [27]. The latter focuses on a compromise solution between individual utility and group utility, by which the alternatives ranking may be deviated due to the differences in subjective weightings $[28,29]$. Similarly, COPRAS is identified by using the utility degree to rank alternatives, which may cause results sensitive to the process of normalization [30]. TOPSIS is more adaptive to qualitative and quantitative information, by discriminating alternatives in terms of their Euclidean distances from the ideal solution [31,32]. It has been identified as reliable and efficient in a number of studies on materials selection, for its easy computation and clear trade-offs among various criteria [33]. In addition, TOPSIS is inherently effective to couple with fuzzy set to tackle the uncertainty involved in decision making on materials selection $[34,35]$.

Engineering designers usually express their preference or judgment in a linguistic environment, which may result in vagueness [36]. The TOPSIS is unable to deal with such vagueness, which calls for improvement [37]. Fuzzy set provides the insight into TOPSIS development, by transforming the linguistic information into fuzzy numbers, to indicate decision maker's preference and judgment [38,39]. However, linguistic variables in an ordinary fuzzy set are not clear enough to express the decision maker's preference by using an exact numerical value of either 0 or $1[40,41]$. In such a case, this study applies intervalued trapezoidal intuitionistic fuzzy number (IVTIFN) to handling ambiguity 
in linguistic information, by which its predetermined numerical interval may better specify the fuzzification in a fixed bounded limit [42].

This study provides a MCDM-based computational approach, which couples IVTIFN with the TOPSISto aid engineers in the selection of commercially available materials. Mahalanobis distance is incorporated into IVTIFN-TOPSIS, to discriminate similarities of alternative materials by eliminating the highly correlated decision criteria. An illustrative case example is given to demonstrate its actual application. The study is expected to provide insight into sustainable design of waste-water piping system, ultimately to improve its sustainability.

\section{Materials and Methods}

\subsection{An Indicator System for Pipe Materials Selection}

An indicator system for pipe materials selection is established, as shown in Figure 1. These indicators are classified into three categories, indicating materials' functional, economic and environmental attributes, to reflect the most crucial criteria that should be considered in materials selection for a piping-system design.

The functional attribute reflects the specific performance that certain material must satisfy [21]. In this study, a number of typical criteria are identified to examine functional performances regarding pipe materials, in order to ensure reliability and reduce environmental risk during waste-water collection and transport, including tensile strength (C1), elastic modulus (C2), linear expansion (C3), scaling resistance (C4), and corrosion resistance (C5). $\mathrm{C} 1$ reflects materials' capability to withstand a maximum load of tensile stress [43]. C2 reflects the ability of materials to resist elastic deformation, while $\mathrm{C} 3$ shows materials' resistibility to deformation caused by temperature change [44,45]. Scaling and corrosion resistance play key roles in pipe materials' functional performance to decrease piping failure [46].

Cost plays an important role in materials selection, by which three criteria are considered, consisting of the materials' marketing price (C6), density (C7) and Hazen-Williams roughness (C8). It is worthy of note that $\mathrm{C} 7$ and $\mathrm{C} 8$ have indirect impacts on the costs of pipeline construction and operation. The pipe material with a larger density may entail a heavier cost on pipeline installation [47]. In addition, the degree of roughness of pipe material is positively correlated with the maintenance cost in sewage transportation [48].

With environmental considerations being gradually immersed into product design, selection of materials focuses on environmental impact throughout a product's entire lifecycle [49]. In such a context, three indicators are proposed to indicate the environmental performance of pipe material: energy consumption (C9), human health risk (C10) and material recyclability (C11). Energy consumption here focuses on the power consumption related to pipeline construction and maintenance, which may contribute to indirect carbon emissions [49]. Health risk indicates the hazard of toxic components released to the workers in the pipe materials' processing and welding [12]. The material recyclability is used to reflect the potentials of waste prevention, thus to reduce landfill disposal of waste materials [50]. 


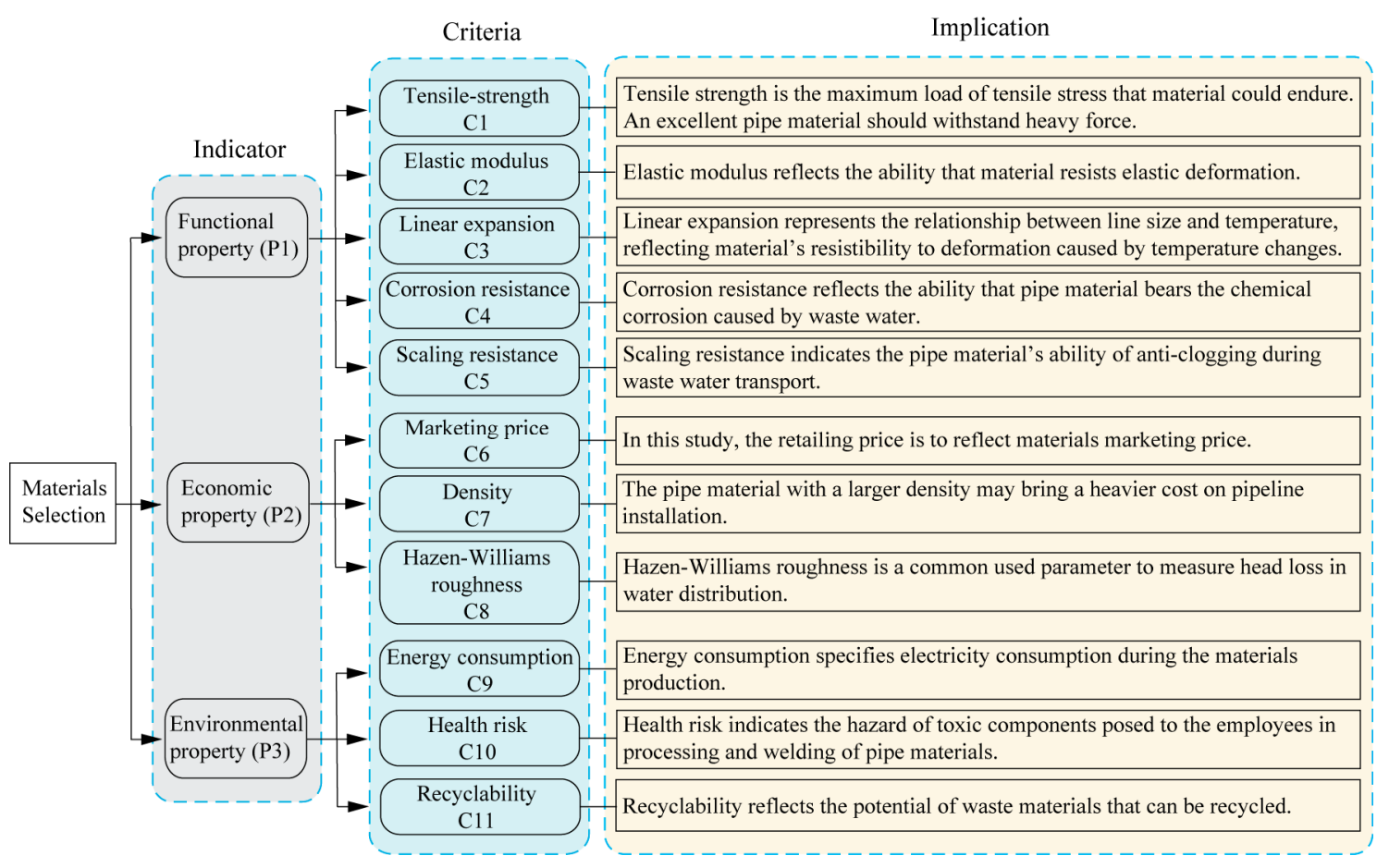

Figure 1. An indicator system of pipe materials selection.

\subsection{Intervalued Trapezoidal Intuitionistic Fuzzy Number}

In this study, the data corresponding to performances of alternatives and preferences on the criteria are mainly determined by engineering designers, which are generally presented in a linguistic way. Thus, IVTIFN is employed to convert such raw data into fuzzy numbers.

A set of IVTIFN (shown in Figure 2) is defined as $\widetilde{A}=\left(\widetilde{A}^{\mathrm{L}}, \widetilde{\mathrm{A}}^{\mathrm{U}}\right)=\left[\left(\mathrm{a}_{1}^{\mathrm{L}}, \mathrm{a}_{2}^{\mathrm{L}}, \mathrm{a}_{3}^{\mathrm{L}}\right) ;\left(\mathrm{a}_{1}^{\mathrm{U}}, \mathrm{a}_{2}^{\mathrm{U}}, \mathrm{a}_{3}^{\mathrm{U}}\right)\right]$, $\left(a_{2}^{\mathrm{L}}=\mathrm{a}_{2}^{\mathrm{U}}=\mathrm{a}_{2}\right)$. The membership function $\left(\mu_{\mathrm{A}_{\mathrm{A}} \mathrm{L}}(\mathrm{x}), \mu_{\tilde{A}_{\mathrm{U}}}(\mathrm{x})\right)$, indicating that what degree the element (x) subordinates to the set, is expressed as follows [51]:

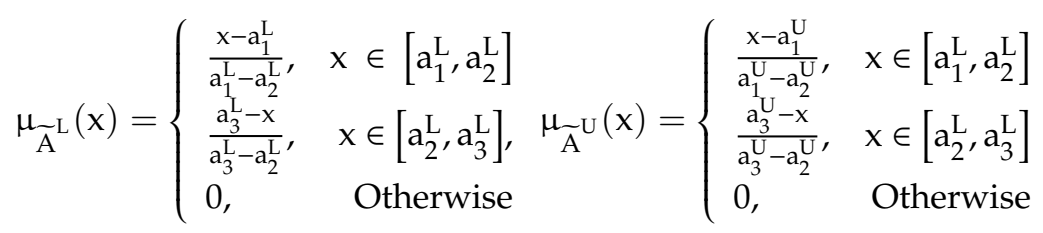




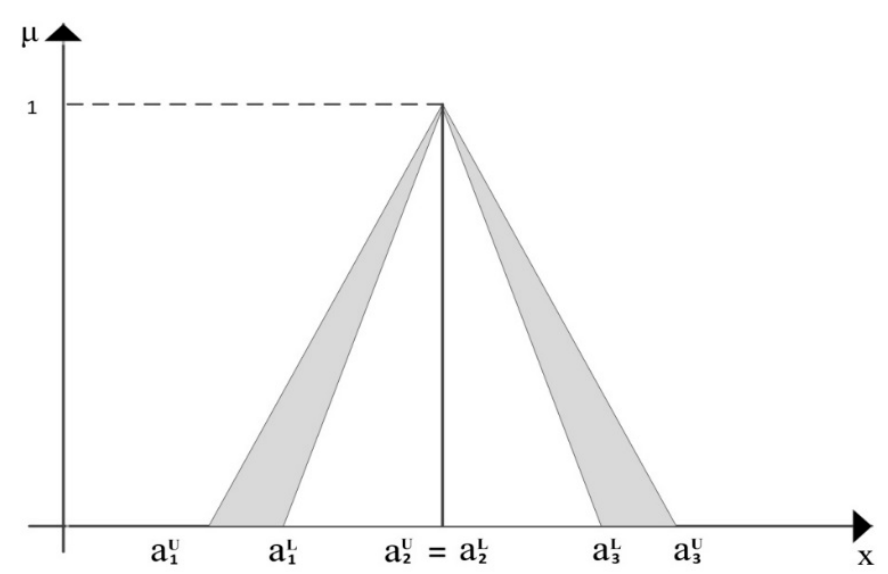

Figure 2. Membership function of intervalued trapezoidal intuitionistic fuzzy number.

Assume that two arbitrary fuzzy numbers are $\widetilde{\alpha}=\left[\left(\alpha_{1}^{\mathrm{L}}, \alpha_{2}^{\mathrm{L}}, \alpha_{3}^{\mathrm{L}}\right) ;\left(\alpha_{1}^{\mathrm{U}}, \alpha_{2}^{\mathrm{U}}, \alpha_{3}^{\mathrm{U}}\right)\right]$, and $\widetilde{\beta}=\left[\left(\beta_{1}^{\mathrm{L}}, \beta_{2}^{\mathrm{L}}, \beta_{3}^{\mathrm{L}}\right) ;\left(\beta_{1}^{\mathrm{U}}, \beta_{2}^{\mathrm{U}}, \beta_{3}^{\mathrm{U}}\right)\right]$, respectively The arithmetic operation for the two fuzzy numbers used in the study is given as follows:

$$
\begin{aligned}
& \widetilde{\alpha}+\widetilde{\beta}=\left[\left(\alpha_{1}^{\mathrm{L}}, \alpha_{2}^{\mathrm{L}}, \alpha_{3}^{\mathrm{L}}\right) ;\left(\alpha_{1}^{\mathrm{U}}, \alpha_{2}^{\mathrm{U}}, \alpha_{3}^{\mathrm{U}}\right)\right]+\left[\left(\beta_{1}^{\mathrm{L}}, \beta_{2}^{\mathrm{L}}, \beta_{3}^{\mathrm{L}}\right) ;\left(\beta_{1}^{\mathrm{U}}, \beta_{2}^{\mathrm{U}}, \beta_{3}^{\mathrm{U}}\right)\right] \\
& =\left[\left(\alpha_{1}^{\mathrm{L}}+\beta_{1}^{\mathrm{L}}, \alpha_{2}^{\mathrm{L}}+\beta_{2}^{\mathrm{L}}, \alpha_{3}^{\mathrm{L}}+\beta_{3}^{\mathrm{L}}\right) ;\left(\alpha_{1}^{\mathrm{U}}+\beta_{1}^{\mathrm{U}}, \alpha_{2}^{\mathrm{U}}+\beta_{2}^{\mathrm{U}}, \alpha_{3}^{\mathrm{U}}+\beta_{3}^{\mathrm{U}}\right)\right] \\
& \widetilde{\alpha}-\widetilde{\beta}=\left[\left(\alpha_{1}^{\mathrm{L}}, \alpha_{2}^{\mathrm{L}}, \alpha_{3}^{\mathrm{L}}\right) ;\left(\alpha_{1}^{\mathrm{U}}, \alpha_{2}^{\mathrm{U}}, \alpha_{3}^{\mathrm{U}}\right)\right]-\left[\left(\beta_{1}^{\mathrm{L}}, \beta_{2}^{\mathrm{L}}, \beta_{3}^{\mathrm{L}}\right) ;\left(\beta_{1}^{\mathrm{U}}, \beta_{2}^{\mathrm{U}}, \beta_{3}^{\mathrm{U}}\right)\right] \\
& =\left[\left(\alpha_{1}^{\mathrm{L}}-\beta_{1}^{\mathrm{L}}, \alpha_{2}^{\mathrm{L}}-\beta_{2}^{\mathrm{L}}, \alpha_{3}^{\mathrm{L}}-\beta_{3}^{\mathrm{L}}\right) ;\left(\alpha_{1}^{\mathrm{U}}-\beta_{1}^{\mathrm{U}}, \alpha_{2}^{\mathrm{U}}-\beta_{2}^{\mathrm{U}}, \alpha_{3}^{\mathrm{U}}-\beta_{3}^{\mathrm{U}}\right)\right] \\
& \widetilde{\alpha} \times \widetilde{\beta}=\left[\left(\alpha_{1}^{\mathrm{L}}, \alpha_{2}^{\mathrm{L}}, \alpha_{3}^{\mathrm{L}}\right) ;\left(\alpha_{1}^{\mathrm{U}}, \alpha_{2}^{\mathrm{U}}, \alpha_{3}^{\mathrm{U}}\right)\right] \times\left[\left(\beta_{1}^{\mathrm{L}}, \beta_{2}^{\mathrm{L}}, \beta_{3}^{\mathrm{L}}\right) ;\left(\beta_{1}^{\mathrm{U}}, \beta_{2}^{\mathrm{U}}, \beta_{3}^{\mathrm{U}}\right)\right] \\
& =\left[\left(\alpha_{1}^{\mathrm{L}} \beta_{1}^{\mathrm{L}}, \alpha_{2}^{\mathrm{L}} \beta_{2}^{\mathrm{L}}, \alpha_{3}^{\mathrm{L}} \beta_{3}^{\mathrm{L}}\right) ;\left(\alpha_{1}^{\mathrm{U}} \beta_{1}^{\mathrm{U}}, \alpha_{2}^{\mathrm{U}} \beta_{2}^{\mathrm{U}}, \alpha_{3}^{\mathrm{U}} \beta_{3}^{\mathrm{U}}\right)\right] \\
& \widetilde{\alpha} \div \widetilde{\beta}=\left[\left(\alpha_{1}^{\mathrm{L}}, \alpha_{2}^{\mathrm{L}}, \alpha_{3}^{\mathrm{L}}\right) ;\left(\alpha_{1}^{\mathrm{U}}, \alpha_{2}^{\mathrm{U}}, \alpha_{3}^{\mathrm{U}}\right)\right] \div\left[\left(\beta_{1}^{\mathrm{L}}, \beta_{2}^{\mathrm{L}}, \beta_{3}^{\mathrm{L}}\right) ;\left(\beta_{1}^{\mathrm{U}}, \beta_{2}^{\mathrm{U}}, \beta_{3}^{\mathrm{U}}\right)\right] \\
& =\left[\left(\alpha_{1}^{\mathrm{L}} / \beta_{1}^{\mathrm{L}}, \alpha_{2}^{\mathrm{L}} / \beta_{2}^{\mathrm{L}}, \alpha_{3}^{\mathrm{L}} / \beta_{3}^{\mathrm{L}}\right) ;\left(\alpha_{1}^{\mathrm{U}} / \beta_{1}^{\mathrm{U}}, \alpha_{2}^{\mathrm{U}} / \beta_{2}^{\mathrm{U}}, \alpha_{3}^{\mathrm{U}} / \beta_{3}^{\mathrm{U}}\right)\right]
\end{aligned}
$$

Assume that the number of involved engineering designers for the pipe materials selection is $e$, and the $k$ th designer's fuzzy rating corresponding to the $j$ th alternative material in the $i$ th criteria is $\widetilde{r}_{\mathrm{ijk}}=\left[\left(\mathrm{r}_{\mathrm{ijk} 1}^{\mathrm{L}}, \mathrm{r}_{\mathrm{ijk} 2}^{\mathrm{L}}, \mathrm{r}_{\mathrm{ijk} 3}^{\mathrm{L}}\right),\left(\mathrm{r}_{\mathrm{ijk} 1}^{\mathrm{U}}, \mathrm{r}_{\mathrm{ijk} 2}^{\mathrm{U}}, \mathrm{r}_{\mathrm{ijk} \mathrm{k} 3}^{\mathrm{U}}\right)\right]$. Thus, the fuzzy ratings of different designers are aggregated as $\widetilde{\mathrm{r}}_{\mathrm{ij}}$, given as follows:

$$
\widetilde{\mathrm{r}}_{\mathrm{ij}}=\left[\left(\mathrm{r}_{\mathrm{ij} 1}^{\mathrm{L}}, \mathrm{r}_{\mathrm{ij} 2}^{\mathrm{L}}, \mathrm{r}_{\mathrm{ij} 3}^{\mathrm{L}}\right),\left(\mathrm{r}_{\mathrm{ij} 1}^{\mathrm{U}}, \mathrm{r}_{\mathrm{ij} 2}^{\mathrm{U}}, \mathrm{r}_{\mathrm{ij} 3}^{\mathrm{U}}\right)\right]=\frac{1}{\mathrm{e}} \sum_{\mathrm{k}=1}^{\mathrm{e}} \widetilde{\mathrm{r}}_{\mathrm{ijk}}
$$

The obtained aggregated ratings need to be normalized, and the normalization procedures are given as follows:

$$
\begin{aligned}
& \widetilde{x}_{i j}=\left[\left(x_{i j 1}^{L}, r_{i j 2}^{L}, x_{i j 3}^{L}\right),\left(x_{i j 1}^{U}, x_{i j 2}^{U}, x_{i j 3}^{U}\right)\right]=\left[\left(\frac{r_{i j 1}^{L}}{r_{j 3}^{U}}, \frac{r_{i j 2}^{L}}{r_{j 3}^{U}}, \frac{r_{i j 3}^{L}}{r_{j 3}^{U}}\right),\left(\frac{r_{i j 1}^{U}}{r_{j 3}^{U}}, \frac{r_{i j 2}^{U}}{r_{j 3}^{U}}, \frac{r_{i j 3}^{U}}{r_{j 3}^{U}}\right)\right], j \in B \\
& \widetilde{x}_{i j}=\left[\left(x_{i j 1}^{L}, x_{i j 2}^{L}, x_{i j 3}^{L}\right),\left(x_{i j 1}^{U}, x_{i j 2}^{U}, x_{i j 3}^{U}\right)\right]=\left[\left(\frac{r_{j 1}^{L}}{r_{i j 3}^{U}}, \frac{r_{j 1}^{L}}{r_{i j 2}^{U}}, \frac{r_{j 1}^{L}}{r_{i j 1}^{U}}\right),\left(\frac{r_{j 1}^{L}}{r_{i j 3}^{L}}, \frac{r_{j 1}^{L}}{r_{i j 2}^{L}}, \frac{r_{j 1}^{L}}{r_{i j 1}^{L}}\right)\right], j \in C
\end{aligned}
$$

where $B$ denotes the beneficial criteria, $r_{j 3}^{U}=\operatorname{maxr}_{i j 3}^{U}$; whilst $C$ represents cost criteria, $r_{j 1}^{L}=\min _{i} r_{i j 1}^{L}$. 
The best and worst value of the $j$ th criterion is denoted as $\widetilde{x}_{j}^{*}=\max _{i} \widetilde{x}_{i j}, \widetilde{x}_{j}^{-}=\min _{i} \widetilde{x}_{i j}$, respectively. The normalized rating is:

$$
\widetilde{a}_{i j}=\frac{\widetilde{x}_{i j}-\widetilde{x}_{j}^{-}}{\widetilde{x}_{j}^{*}-\widetilde{x}_{j}^{-}}
$$

The normalized matrix of ratings is thus constructed:

$$
\mathrm{A}=\left[\begin{array}{ccc}
\widetilde{\mathrm{a}}_{11} & \cdots & \widetilde{\mathrm{a}}_{1 \mathrm{n}} \\
\vdots & \ddots & \vdots \\
\widetilde{\mathrm{a}}_{\mathrm{m} 1} & \cdots & \widetilde{\mathrm{a}}_{\mathrm{mn}}
\end{array}\right]
$$

where $m$ indicates the number of material alternatives, $n$ is the number of evaluation criteria.

The engineering designers may also apply linguistic remarks, including Excellent (E), Good (G), Fair (F), Poor (P), Very Poor (VP), to classify alternatives' performance with respect to each criterion. This performances of the alternative materials are by analogy to such remarks, and are converted into corresponding fuzzy numbers, shown in Table 1.

Table 1. Transformation of linguistic remarks to fuzzy numbers.

\begin{tabular}{ccc}
\hline \multicolumn{2}{c}{ Linguistic Remark } & \multirow{2}{*}{ Fuzzy Number } \\
\cline { 1 - 2 } Performances of Alternatives & Relative Importance of Criteria & \\
\hline Very Poor (VP) & Extremely Low (EL) & $((0.1,0.1,0.2),(0.05,0.1,0.25))$ \\
Poor (P) & Low (L) & $((0.2,0.3,0.4),(0.15,0.3,0.45))$ \\
Fair (F) & Medium (M) & $((0.4,0.5,0.6),(0.35,0.5,0.65))$ \\
Good (G) & High (H) & $((0.6,0.7,0.8),(0.55,0.7,0.85))$ \\
Excellent (E) & Extremely High (EH) & $((0.8,0.9,0.9),(0.75,0.9,0.95))$ \\
\hline
\end{tabular}

Assume the weightings of the $j$ th criteria assessed by the $k$ th designer is $\widetilde{\mathrm{z}}_{\mathrm{jk}}=\left[\left(\mathrm{z}_{\mathrm{jk} 1}^{\mathrm{L}}, \mathrm{z}_{\mathrm{jk} 2}^{\mathrm{L}}, \mathrm{z}_{\mathrm{jk} 3}^{\mathrm{L}}\right),\left(\mathrm{z}_{\mathrm{jk1} 1}^{\mathrm{U}}, \mathrm{z}_{\mathrm{jk} 2}^{\mathrm{U}}, \mathrm{z}_{\mathrm{jk} 3}^{\mathrm{U}}\right)\right]$. The obtained fuzzy weightings are aggregated as follows:

$$
\widetilde{\mathrm{z}}_{\mathrm{j}}=\left[\left(\mathrm{z}_{\mathrm{j} 1}^{\mathrm{L}}, \mathrm{z}_{\mathrm{j} 2}^{\mathrm{L}}, \mathrm{z}_{\mathrm{j} 3}^{\mathrm{L}}\right),\left(\mathrm{z}_{\mathrm{j} 1}^{\mathrm{U}}, \mathrm{z}_{\mathrm{j} 2}^{\mathrm{U}}, \mathrm{z}_{\mathrm{j} 3}^{\mathrm{U}}\right)\right]=\frac{1}{\mathrm{e}} \sum_{\mathrm{k}=1}^{\mathrm{e}} \widetilde{\mathrm{j}}_{\mathrm{jk}}
$$

To facilitate TOPSIS application, the obtained weightings shown in Equation (11) have to be normalized as follows:

$$
\widetilde{\mathrm{w}}_{\mathrm{j}}=\frac{\widetilde{\mathrm{z}}_{\mathrm{j}}}{\sum_{\mathrm{j}} \widetilde{\mathrm{z}}_{\mathrm{j}}}
$$

Thus, the weighting matrix is constructed as follows:

$$
\mathrm{w}=\operatorname{diag}\left(\widetilde{\mathrm{w}}_{1}, \widetilde{\mathrm{w}}_{2}, \cdots, \widetilde{\mathrm{w}}_{\mathrm{n}}\right)
$$

\subsection{TOPSIS}

The above normalized ratings of material alternatives and the related weightings are input into TOPSIS to obtain the distances between alternatives and the best/least alternative. These distances are based on Euclidean distance (IVTIFN-TOPSIS (E)) and Mahalanobis distance (IVTIFN-TOPSIS (M)) respectively, to calculate their closeness coefficients for ranking the material alternatives.

The Euclidean distances between the material alternatives and the best/least alternative are specified as follows:

$$
\widetilde{\mathrm{D}}_{\mathrm{Ei}}^{+}=\sqrt{\sum_{\mathrm{j}}\left[\widetilde{\mathrm{w}}_{\mathrm{j}}\left(\widetilde{\mathrm{a}}_{\mathrm{ij}}-\widetilde{\mathrm{a}}_{\mathrm{j}}^{*}\right)\right]^{2}}
$$




$$
\widetilde{\mathrm{D}}_{\mathrm{Ei}}^{-}=\sqrt{\sum_{\mathrm{j}}\left[\widetilde{\mathrm{w}}_{\mathrm{j}}\left(\widetilde{\mathrm{a}}_{\mathrm{ij}}-\widetilde{\mathrm{a}}_{\mathrm{j}}^{-}\right)\right]^{2}}
$$

The closeness coefficient is:

$$
\widetilde{\mathrm{C}}_{\mathrm{Ei}}=\frac{\widetilde{\mathrm{D}}_{\mathrm{Ei}}^{-}}{\widetilde{\mathrm{D}_{\mathrm{Ei}}^{-}}+\widetilde{\mathrm{D}}_{\mathrm{Ei}}^{+}}
$$

where $\widetilde{\mathrm{C}}_{\mathrm{Ei}}=\left[\left(\mathrm{c}_{\mathrm{Ei} 1}^{\mathrm{L}}, \mathrm{c}_{\mathrm{Ei} 2}^{\mathrm{L}}, \mathrm{c}_{\mathrm{Ei} 3}^{\mathrm{L}}\right),\left(\mathrm{c}_{\mathrm{Ei} 1}^{\mathrm{U}}, \mathrm{c}_{\mathrm{Ei} 2}^{\mathrm{U}}, \mathrm{c}_{\mathrm{Ei} 3}^{\mathrm{U}}\right)\right]$.

A defuzzification method, center of gravity (COG), is applied to converting fuzzy numbers $\widetilde{C}_{\mathrm{Ei}}$ into crisp scores $\mathrm{C}_{\mathrm{Ei}}$ to rank the alternatives, given as follows [52]:

$$
C_{E i}=\sqrt{C_{E i}^{L} \times C_{E i}^{U}}=\sqrt{\frac{\int \mu_{C_{E i}}^{L}(x) x d x}{\int \mu_{C_{E i}}^{L}(x) d x} \times \frac{\int \mu_{C_{E i}^{U}}^{U}(x) x d x}{\int \mu_{C_{E i}}^{U}(x) d x}}
$$

The greater $\mathrm{C}_{\mathrm{Ei}}$ is, the better the corresponding material is.

The Mahalanobis distances between alternatives and the best/least alternative are:

$$
\begin{gathered}
\widetilde{D}_{M i}^{+}=\sqrt{\left(A_{i}-A^{*}\right)^{T} w^{T} \Sigma^{-1} w\left(A_{i}-A^{*}\right)} \\
\widetilde{D}_{M i}^{-}=\sqrt{\left(A_{i}-A^{-}\right)^{T} w^{T} \Sigma^{-1} w\left(A_{i}-A^{-}\right)}
\end{gathered}
$$

where $A_{i} A^{*}$, and $A^{-}$indicates the $i$ th material alternative, the best alternative and the least alternative, respectively, $A_{i}=\left(\widetilde{a}_{i 1}, \widetilde{a}_{i 2}, \cdots, \widetilde{a}_{i n}\right)^{T}, A^{*}=\left(\widetilde{a}_{1}^{*}, \widetilde{a}_{2}, \cdots, \widetilde{a}_{n}^{*}\right)^{T}, A^{-}=\left(\widetilde{a}_{1}, \widetilde{a}_{2}, \cdots, \widetilde{a}_{n}\right)^{T}\left(\widetilde{a}_{j}^{*}=\max _{i} \widetilde{a}_{i j}\right.$, $\widetilde{a_{j}}=\min _{i}\left(\widetilde{a}_{i j}\right) . \Sigma$ is the co-variance matrix of A. If $\Sigma$ is indicated as a singular matrix, the Moore-Penrose generalized inverse matrix $\Sigma^{-1}$ is used to replace $\Sigma$ [53].

The closeness coefficient is:

$$
\widetilde{\mathrm{C}}_{\mathrm{Mi}}=\frac{\widetilde{\mathrm{D}}_{\mathrm{Mi}}^{-}}{\widetilde{\mathrm{D}}_{\mathrm{Mi}}^{-}+\widetilde{\mathrm{D}}_{\mathrm{Mi}}^{+}}
$$

where $\widetilde{\mathrm{C}}_{\mathrm{Mi}}=\left[\left(\mathrm{c}_{\mathrm{Mi} 1}^{\mathrm{L}}, \mathrm{c}_{\mathrm{Mi} 2}^{\mathrm{L}}, \mathrm{c}_{\mathrm{Mi} 3}^{\mathrm{L}}\right),\left(\mathrm{c}_{\mathrm{Mi}}^{\mathrm{U}}, \mathrm{c}_{\mathrm{Mi} 2}^{\mathrm{U}}, \mathrm{c}_{\mathrm{Mi} 3}^{\mathrm{U}}\right)\right]$.

Similarly, the fuzzy numbers $\widetilde{\mathrm{C}}_{\mathrm{Mi}}$ is converted into crisp scores $\mathrm{C}_{\mathrm{Mi}}$ to rank the alternatives. The greater $\mathrm{C}_{\mathrm{Mi}}$ is, the better the corresponding material is.

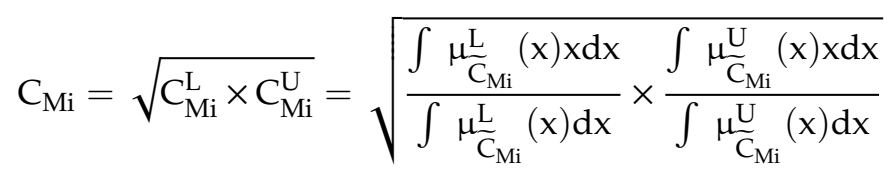

\section{An Illustrative Case Example}

The case example is to conduct materials selection for waste-water piping in a newly constructed municipal sewage treatment plant in Chengdu City, China. According to the design requirements, the nominal diameter of the pipeline is $200 \mathrm{~mm}$, which has to tolerate the pressure of $1.6 \mathrm{MPa}$. Currently, there is a wide variety of commercial pipe materials on the market, including carbon steels, copper, ductile iron, polyethylene (PE), polyvinyl chloride (PVC), pentatricopeptide repeats (PPR), etc. Given their applications to sewage treatment, this study chooses four common pipe materials, i.e., carbon steel (M1), galvanized steel (M2), PVC (M3) and high-density PE (HDPE) (M4) for further precise selection.

A group comprised of five experienced engineers has been involved in the consultation on pipe materials selection, including two project managers from the treatment plant and three engineers who are engaged in the design of sewage collection and transportation system. Their subjective 
judgments on the performances of the four alternative materials in respect to each criterion are given in Table 2. Table 3 shows the subjective judgments of the five involved engineers on the importance of the proposed criteria.

Table 2. Subjective judgments on performances of the alternative materials.

\begin{tabular}{|c|c|c|c|c|c|c|c|c|c|c|c|c|}
\hline & & $\mathrm{C} 1$ & $\mathrm{C} 2$ & $\mathrm{C} 3$ & $\mathrm{C} 4$ & C5 & C6 & $\mathrm{C} 7$ & $\mathrm{C} 8$ & C9 & C10 & C11 \\
\hline \multirow{4}{*}{ Engineer 1} & M1 & $E$ & E & VP & VP & VP & G & G & $F$ & G & G & G \\
\hline & M2 & E & E & VP & $\mathrm{P}$ & $\mathrm{P}$ & E & G & F & E & $\mathrm{E}$ & $\mathrm{E}$ \\
\hline & M3 & F & F & $\mathrm{F}$ & G & G & $P$ & $\mathrm{P}$ & $E$ & P & $\mathrm{P}$ & $\mathrm{P}$ \\
\hline & M4 & $\mathrm{P}$ & $\mathrm{P}$ & E & $\mathrm{E}$ & E & F & VP & G & $\mathrm{P}$ & VP & VP \\
\hline \multirow{4}{*}{ Engineer 2} & M1 & E & E & F & $\mathrm{P}$ & $\mathrm{P}$ & E & $\mathrm{E}$ & F & $\mathrm{E}$ & $\mathrm{E}$ & G \\
\hline & M2 & E & E & F & $\mathrm{P}$ & $\mathrm{P}$ & E & E & F & E & E & G \\
\hline & M3 & $\mathrm{F}$ & $\mathrm{F}$ & G & G & G & $\mathrm{P}$ & $\mathrm{P}$ & E & $\mathrm{P}$ & $\mathrm{P}$ & $\mathrm{F}$ \\
\hline & M4 & VP & VP & E & $\mathrm{E}$ & E & $\mathrm{F}$ & VP & G & $\mathrm{P}$ & $\mathrm{P}$ & $\mathrm{P}$ \\
\hline \multirow{4}{*}{ Engineer 3} & M1 & E & $E$ & $P$ & $\mathrm{P}$ & VP & F & $G$ & F & $G$ & G & G \\
\hline & M2 & $\mathrm{P}$ & VP & G & G & G & $P$ & $P$ & G & $\mathrm{P}$ & $\mathrm{F}$ & $\mathrm{P}$ \\
\hline & M3 & F & $\mathrm{F}$ & $\mathrm{E}$ & $\mathrm{E}$ & $\mathrm{E}$ & F & $\mathrm{P}$ & G & VP & $\mathrm{P}$ & VP \\
\hline & M4 & E & E & VP & VP & VP & G & G & $\mathrm{F}$ & G & G & G \\
\hline \multirow{4}{*}{ Engineer 4} & M1 & $E$ & $E$ & VP & $P$ & $P$ & $E$ & G & $F$ & $E$ & $E$ & $E$ \\
\hline & M2 & $\mathrm{F}$ & $\mathrm{F}$ & $\mathrm{F}$ & G & G & $\mathrm{P}$ & $\mathrm{P}$ & $\mathrm{E}$ & P & $\mathrm{P}$ & $\mathrm{P}$ \\
\hline & M3 & $\mathrm{P}$ & $\mathrm{P}$ & E & $\mathrm{E}$ & $\mathrm{E}$ & F & VP & G & $P$ & VP & VP \\
\hline & M4 & $\mathrm{E}$ & E & $\mathrm{F}$ & $\mathrm{P}$ & $\mathrm{P}$ & E & $\mathrm{E}$ & $\mathrm{F}$ & E & $\mathrm{E}$ & G \\
\hline \multirow{4}{*}{ Engineer 5} & M1 & $E$ & $E$ & $\mathrm{~F}$ & $\mathrm{P}$ & $\mathrm{P}$ & E & $E$ & F & E & $E$ & G \\
\hline & M2 & $\mathrm{F}$ & $\mathrm{F}$ & G & G & G & $P$ & $\mathrm{P}$ & E & $P$ & $P$ & $\mathrm{~F}$ \\
\hline & M3 & VP & VP & $\mathrm{E}$ & $\mathrm{E}$ & $\mathrm{E}$ & $\mathrm{F}$ & VP & G & $\mathrm{P}$ & $\mathrm{P}$ & $\mathrm{P}$ \\
\hline & M4 & $\mathrm{E}$ & $\mathrm{E}$ & $\mathrm{P}$ & $\mathrm{P}$ & VP & $\mathrm{F}$ & G & $\mathrm{F}$ & G & G & G \\
\hline
\end{tabular}

Table 3. Subjective judgments on the importance of the proposed criteria.

\begin{tabular}{|c|c|c|c|c|c|c|}
\hline \multicolumn{2}{|l|}{ Criteria } & Engineer 1 & Engineer 2 & Engineer 3 & Engineer 4 & Engineer 5 \\
\hline \multirow{5}{*}{$\begin{array}{l}\text { Functional } \\
\text { attribute }\end{array}$} & $\mathrm{C} 1$ & EL & $\mathrm{L}$ & $\mathrm{L}$ & $\mathrm{L}$ & EL \\
\hline & $\mathrm{C} 2$ & EL & $\mathrm{L}$ & EL & $\mathrm{L}$ & EL \\
\hline & C3 & EL & EL & EL & EL & EL \\
\hline & $\mathrm{C} 4$ & $\mathrm{EH}$ & $\mathrm{H}$ & $\mathrm{H}$ & $\mathrm{H}$ & $\mathrm{EH}$ \\
\hline & C5 & $\mathrm{EH}$ & $\mathrm{EH}$ & $\mathrm{H}$ & $\mathrm{H}$ & $\mathrm{H}$ \\
\hline \multirow{3}{*}{$\begin{array}{l}\text { Economic } \\
\text { attribute }\end{array}$} & C6 & $\mathrm{EH}$ & $\mathrm{EH}$ & $\mathrm{EH}$ & $\mathrm{EH}$ & $\mathrm{EH}$ \\
\hline & $\mathrm{C} 7$ & $\mathrm{~L}$ & $\mathrm{M}$ & $\mathrm{L}$ & $\mathrm{L}$ & $\mathrm{L}$ \\
\hline & $\mathrm{C} 8$ & $\mathrm{~L}$ & M & M & $\mathrm{L}$ & $\mathrm{L}$ \\
\hline \multirow{3}{*}{$\begin{array}{l}\text { Environmental } \\
\text { attribute }\end{array}$} & C9 & EL & EL & EL & EL & EL \\
\hline & C10 & EL & EL & $\mathrm{L}$ & $\mathrm{L}$ & $\mathrm{L}$ \\
\hline & $\mathrm{C} 11$ & EL & EL & $\mathrm{L}$ & $\mathrm{L}$ & $\mathrm{L}$ \\
\hline
\end{tabular}

\section{Results and Discussion}

\subsection{Evaluation Results}

Table 4 shows that the ranking result from the IVTIFN-TOPSIS (E) model is M3 $>$ M4 $>$ M1 $>$ M2. It is clear that two optional plastic materials, i.e., PVC (M3) and HDPE (M4), are the optimal and near-optimal materials. Figure 3 shows that they have excellent performances in most criteria. For instance, PVC and HDPE show better capacities in corrosive resistance (C4) and scaling resistance (C5), which are the key functional premises to ensure the liability of the piping system. In contrast to M3 and M4, they have their own advantages and disadvantages. PVC shows superiorities in mechanical properties (C1 and C2), marketing price (C6) and roughness (C8). Nevertheless, HDPE is more environmentally-friendly and capable of anti-corrosion. By taking the relative importance of criteria into consideration, the most appropriate material for waste-water piping is PVC (M3). M1 performs better than M2 in most of the evaluation criteria, excepting C4 and C5. 
Table 4. Results of the IVTIFN-TOPSIS (E) model.

\begin{tabular}{|c|c|c|c|c|c|}
\hline Model & M1 & & & M3 & M4 \\
\hline \multirow{2}{*}{ IVTIFN-TOPSIS (E) } & $\mathrm{C}_{\mathrm{Ei}}$ & 0.3272 & 0.2185 & 0.7170 & 0.6426 \\
\hline & Ranking order & 3 & 4 & 1 & 2 \\
\hline
\end{tabular}

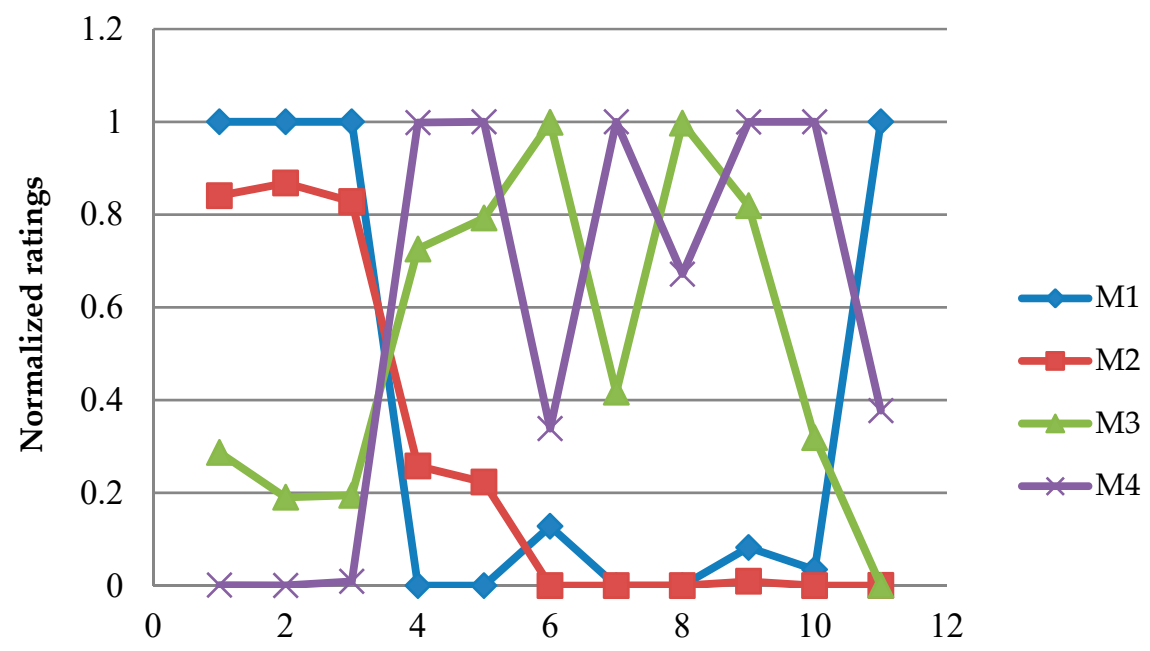

Criterion

Figure 3. Performance comparisons among the four alternative materials.

A correlation test is conducted to examine the correlation among criteria by using Pearson analysis, through which Table 5 shows that a number of criteria are significantly correlated to each other, highlighted by the functional attributes, i.e., among $\mathrm{C} 1$ to $\mathrm{C} 5$.

Table 5. Correlation matrix of the evaluation criteria.

\begin{tabular}{cccccccccccc}
\hline Criteria & C1 & C2 & C3 & C4 & C5 & C6 & C7 & C8 & C9 & C10 & C11 \\
\hline C1 & 1 & 0.9949 & 0.9951 & -0.996 & -0.996 & -0.576 & -0.952 & -0.854 & -0.974 & -0.907 & 0.4032 \\
C2 & 0.9949 & 1 & 0.9996 & -0.987 & -0.996 & -0.655 & -0.924 & -0.902 & -0.985 & -0.87 & 0.4158 \\
C3 & 0.9951 & 0.9996 & 1 & -0.99 & -0.998 & -0.652 & -0.92 & -0.9 & -0.98 & -0.864 & 0.4396 \\
C4 & -0.996 & -0.987 & -0.99 & 1 & 0.9966 & 0.5508 & 0.9364 & 0.8357 & 0.9499 & 0.8906 & -0.476 \\
C5 & -0.996 & -0.996 & -0.998 & 0.9966 & 1 & 0.6165 & 0.9224 & 0.8779 & 0.9665 & 0.869 & -0.473 \\
C6 & -0.576 & -0.655 & -0.652 & 0.5508 & 0.6165 & 1 & 0.3526 & 0.9172 & 0.6853 & 0.2399 & -0.407 \\
C7 & -0.952 & -0.924 & -0.92 & 0.9364 & 0.9224 & 0.3526 & 1 & 0.6882 & 0.9967 & 0.9922 & -0.16 \\
C8 & -0.854 & -0.902 & -0.9 & 0.8357 & 0.8779 & 0.9172 & 0.6882 & 1 & 0.9108 & 0.5947 & -0.455 \\
C9 & -0.974 & -0.985 & -0.98 & 0.9499 & 0.9665 & 0.6853 & 0.9967 & 0.9108 & 1 & 0.8713 & -0.274 \\
C10 & -0.907 & -0.87 & -0.864 & 0.8906 & 0.869 & 0.2399 & 0.9922 & 0.5947 & 0.8713 & 1 & -0.077 \\
C11 & 0.4032 & 0.4158 & 0.4396 & -0.476 & -0.473 & -0.407 & -0.16 & -0.455 & -0.274 & -0.077 & 1 \\
\hline
\end{tabular}

The major purpose of the materials selection is to ensure reliable piping of waste water, by which anticorrosion and anticlogging are the prerequisites. The criteria C4 and C5 have directly reflected such functional performances. Although $\mathrm{C} 1, \mathrm{C} 2$, and $\mathrm{C} 3$ have certain relationships linked with pipe reliability, their performances on waste-water piping are in a lower priority in contrast to C4 and C5. In such context, they are eliminated from the eleven proposed criteria to decrease information overlapping. Mahalanobis distance is further employed to examine whether the ranking results are varied.

Table 6 shows that the materials alternative ranking by using IVTIFN-TOPSIS (M) is M4 > M3 > M2 > M1. Compared with the result by using the IVTIFN-TOPSIS (E), it is clear that HDPE is regarded as the optimal material, whilst carbon steel is the least suitable option. 
Table 6. Results of the IVTIFN-TOPSIS (M) model.

\begin{tabular}{|c|c|c|c|c|c|}
\hline Model & M1 & \multicolumn{2}{|c|}{ M2 } & M3 & M4 \\
\hline \multirow{2}{*}{ IVTIFN-TOPSIS (M) } & $\mathrm{C}_{\mathrm{Mi}}$ & 0.1461 & 0.3269 & 0.6430 & 0.7094 \\
\hline & Ranking order & 4 & 3 & 2 & 1 \\
\hline
\end{tabular}

\subsection{Discussion}

Both of the results from the IVTIFN-TOPSIS (E) and the IVTIFN-TOPSIS (M) model indicate that polymers are superior to the metal materials, which are consistent with that of Petit-Boix et al. [54] indicating that plastic materials are suitable for sewage transport due to their excellent performances on anticorrosion. Zhao et al. [12] combined AHP with gray relational analysis to select similar plastic pipes for heating systems, through which PVC showed great advantages in cost saving, and PE was better in its performance on anticlogging. Li further identified that HDPE was commonly used in landfill leachate transport due to its receptivity to highly concentrated organic matter [55]. Such a result may validate the rationality of our ranking results. Anojkumar et al. [6] further identified that there was no significant difference in the application of TOPSIS and VIKOR to pipe materials selection, but the former is much simpler and time-saving in computation. This may reflect the feasibility of our proposed approach.

From the subjective judgment of the interviewed engineers, they attached great importance to the price, corrosion resistance, and scaling resistance regarding the selection of pipe materials. Such focus indicates that cost and functional properties are still the key drivers in materials selection [56]. However, the engineers pay little attention to the environmental attributes of materials, which reflects that environmental management has not taken as a significant criterion in engineering design [49]. With raw materials being increasingly extracted, engineering design has to consider a transition towards sustainability, not only to follow the economic bottom line, but also to improve the environmental performance [57].

\section{Conclusions}

This study employs IVTIFN-TOPSIS to select materials for waste-water piping, in which IVTIFN is used to deal with subjective and linguistic information. To overcome information overlapping and overestimation of evaluation criteria, Mahalanobis distance is introduced to improve the computational approach by elimination of highly correlated criteria.

A case example is to verify the model application, to conduct materials selection for waste-water piping in a municipal treatment plant. Except for general attention given to the materials' functionalities, i.e., anticorrosion and anticlogging, the economic and environmental attributes have been taken into consideration, to increase the sustainability of material selection. Four commonly-available commercial materials, including PVC, HDPE, carbon steel, and galvanized steel are taken as the available alternatives. Both of the results from the IVTIFN-TOPSIS (E) and the IVTIFN-TOPSIS (M) model show that plastic pipes are better than the metal material alternatives. In particular, HDPE is the optimal material, whilst PVC is near optimal for the piping system design.

The study is expected to provide insight into sustainable design of waste-water piping system. However, there are limitations remaining in the proposed method. The materials' performances in respect of each criterion are mainly evaluated by the five invited engineers, whose judgments are fully dependent upon their empirical experiences. This further may result in deliberate preferences in the selection process. Future study will center on the quantification of the materials' performances regarding functional, economic and environmental attributes, thus to reinforce the objectivity of the decision making.

Author Contributions: R.Z. was involved in conceptualizing the whole study and writing the whole paper. Y.H. implemented the calculation and analysis. Y.Y. proposed the model. S.G. collected the data. 
Funding: This study is sponsored by the National Natural Science Foundation of China (No. 41571520), Sichuan Provincial Young Talent Scientific Funding (No. 2019JDJQ0020), Sichuan Science and Technology Program (No. 2019JDTD0024; No. 2019ZHCG0048), Sichuan Province Circular Economy Research Center Fund (No. XHJJ-1802).

Conflicts of Interest: The authors declare that there is no conflict of interest regarding the publication of this paper.

\section{References}

1. Xia, Y.; Zhang, H.; Phoungthong, K.; Shi, D.X.; Shen, W.H.; Shao, L.M.; He, P.J. Leaching characteristics of calcium-based compounds in MSWI Residues: From the viewpoint of clogging risk. Waste Manag. 2015, 42, 93-100. [CrossRef] [PubMed]

2. Maniya, K.; Bhatt, M.G. A selection of material using a novel type decision-making method: Preference selection index method. Mater. Des. 2010, 31, 1785-1789. [CrossRef]

3. Zhou, C.C.; Yin, G.F.; Hu, X.B. Multi-objective optimization of material selection for sustainable products: Artificial neural networks and genetic algorithm approach. Materi. Des. 2009, 30, 1209-1215. [CrossRef]

4. Albiñana, J.C.; Vila, C. A framework for concurrent material and process selection during conceptual product design stages. Mater. Des. 2012, 41, 433-446. [CrossRef]

5. Mercer, K. Choosing the Right Pipe. J. Am. Water Works Ass. 2013, 105, 10-12. [CrossRef]

6. Anojkumar, L.; Ilangkumaran, M.; Sasirekha, V. Comparative analysis of MCDM methods for pipe material selection in sugar industry. Expert Syst. Appl. 2014, 41, 2964-2980. [CrossRef]

7. Zhang, W.W.; Wang, C.L.; Chen, R.H.; Tian, W.X.; Su, G.H. Preliminary design and thermal analysis of a liquid metal heat pipe radiator for TOPAZ-II power system. Ann. Nucl. Energy 2016, 97, 208-220. [CrossRef]

8. Jahan, A.; Ismail, M.Y.; Mustapha, F.; Sapuan, S.M. Material selection based on ordinal data. Mater. Des. 2010, 31, 3180-3187. [CrossRef]

9. İpek, M.; Selvi, İ.H.; Findik, F.; Torkul, O.; Cedimoğlu, I.H. An expert system based material selection approach to manufacturing. Mater. Des. 2013, 47, 331-340. [CrossRef]

10. Kayfeci, M. Determination of energy saving and optimum insulation thicknesses of the heating piping systems for different insulation materials. Energy Build. 2014, 69, 278-284. [CrossRef]

11. Mendrinos, D.; Katsantonis, S.; Karytsas, C. Pipe materials for borehole heat exchangers. In Proceedings of the European Geothermal Congress, Strasbourg, France, 19-24 September 2016.

12. Zhao, R.; Su, H.; Chen, X. Commercially available materials selection in sustainable design: An integrated multi-attribute decision making approach. Sustainability 2016, 8, 79. [CrossRef]

13. Hosseinijou, S.A.; Mansour, S.; Shirazi, M.A. Social life cycle assessment for material selection: A case study of building materials. Int. J. Life Cycle Ass. 2014, 19, 620-645. [CrossRef]

14. Du, F.; Woods, G.J.; Kang, D. Life cycle analysis for water and wastewater pipe materials. J. Environ. Eng. 2012, 139, 703-711. [CrossRef]

15. Akhtar, S.; Reza, B.; Hewage, K.; Shahriar, A.; Zargar, A.; Sadiq, R. Life cycle sustainability assessment (LCSA) for selection of sewer pipe materials. Clean Technol. Envir. 2015, 17, 973-992. [CrossRef]

16. Zavadskas, E.K.; Turskis, Z.; Kildienè, S. State of art surveys of overviews on MCDM/MADM methods. Technol. Econ. Dev. Econ. 2014, 20, 165-179. [CrossRef]

17. Tian, G.; Zhang, H.; Feng, Y.; Wang, D.; Peng, Y.; Jia, H. Green decoration materials selection under interior environment characteristics: A grey-correlation based hybrid MCDM method. Renew. Sust. Energ. Rev. 2018, 81, 682-692. [CrossRef]

18. Velasquez, M.; Hester, P.T. An analysis of multi-criteria decision making methods. Int. J. Oper. Res. 2013, $10,56-66$.

19. Ghorbanzadeh, O.; Moslem, S.; Blaschke, T.; Duleba, S. Sustainable Urban Transport Planning Considering Different Stakeholder Groups by an Interval-AHP Decision Support Model. Sustainability 2018, 11, 9. [CrossRef]

20. Duleba, S.; Moslem, S. Examining Pareto optimality in analytic hierarchy process on real Data: An application in public transport service development. Expert Syst. Appl. 2019, 116, 21-30. [CrossRef]

21. Vahdani, B.; Mousavi, S.M.; Tavakkoli-Moghaddam, R.; Hashemi, H. A new design of the elimination and choice translating reality method for multi-criteria group decision-making in an intuitionistic fuzzy environment. Appl. Math. Model. 2013, 37, 1781-1799. [CrossRef] 
22. Chatterjee, P.; Athawale, V.M.; Chakraborty, S. Selection of materials using compromise ranking and outranking methods. Mater. Des. 2009, 30, 4043-4053. [CrossRef]

23. Behzadian, M.; Kazemzadeh, R.B.; Albadvi, A.; Aghdasi, M. PROMETHEE: A comprehensive literature review on methodologies and applications. Eur. J. Oper. Res. 2010, 200, 198-215. [CrossRef]

24. Mulliner, E.; Malys, N.; Maliene, V. Comparative analysis of MCDM methods for the assessment of sustainable housing affordability. Omega 2016, 59, 146-156. [CrossRef]

25. Rashidi, M.; Ghodrat, M.; Samali, B.; Kendall, B.; Zhang, C.W. Remedial Modelling of Steel Bridges through Application of Analytical Hierarchy Process (AHP). Appl. Sci. 2017, 7, 168. [CrossRef]

26. Mousavi-Nasab, S.H.; Sotoudeh-Anvari, A. A new multi-criteria decision making approach for sustainable material selection problem: A critical study on rank reversal problem. J. Clean. Prod. 2018, 182, 466-484. [CrossRef]

27. Mousavi-Nasab, S.H.; Sotoudeh-Anvari, A. A comprehensive MCDM-based approach using TOPSIS, COPRAS and DEA as an auxiliary tool for material selection problems. Mater. Des. 2017, 121, 237-253. [CrossRef]

28. Jahan, A.; Edwards, K.L. VIKOR method for material selection problems with interval numbers and target-based criteria. Mater. Des. 2013, 47, 759-765. [CrossRef]

29. Zhang, N.; Wei, G. Extension of VIKOR method for decision making problem based on hesitant fuzzy set. Appl. Math. Model. 2013, 37, 4938-4947. [CrossRef]

30. Bairagi, B.; Dey, B.; Sarkar, B.; Sanyal, S. Selection of robot for automated foundry operations using fuzzy multi-criteria decision making approaches. Int. J. Manag. Sci. Eng. Manag. 2014, 9, 221-232. [CrossRef]

31. Yazdani, M.; Payam, A.F. A comparative study on material selection of microelectromechanical systems electrostatic actuators using Ashby, VIKOR and TOPSIS. Mater. Des. 2015, 65, 328-334. [CrossRef]

32. Feng, Y.X.; Zhang, Z.F.; Tian, G.D.; Fathollahi-Fard, A.M.; Hao, N.N.; Li, Z.W.; Wang, W.J.; Tan, J.R. A Novel Hybrid Fuzzy Grey TOPSIS Method: Supplier Evaluation of a Collaborative Manufacturing Enterprise. Appl. Sci. 2019, 9, 3770. [CrossRef]

33. Govindan, K.; Khodaverdi, R.; Jafarian, A. A fuzzy multi criteria approach for measuring sustainability performance of a supplier based on triple bottom line approach. J. Clean. Prod. 2013, 47, 345-354. [CrossRef]

34. He, Y.H.; Wang, L.B.; He, Z.Z.; Xie, M. A fuzzy TOPSIS and Rough Set based approach for mechanism analysis of product infant failure. Eng. Appl. Artif. Intel. 2016, 47, 25-37. [CrossRef]

35. Falqi, I.I.; Ahmed, M.; Mallick, J. Siliceous Concrete Materials Management for Sustainability Using Fuzzy-TOPSIS Approach. Appl. Sci. 2019, 9, 3457. [CrossRef]

36. Maity, S.R.; Chakraborty, S. Grinding wheel abrasive material selection using fuzzy TOPSIS method. Mater. Manuf. Process. 2013, 28, 408-417. [CrossRef]

37. Şengül, Ü.; Eren, M.; Shiraz, S.E.; Gezder, V.; Şengül, A.B. Fuzzy TOPSIS method for ranking renewable energy supply systems in Turkey. Renew. Energ. 2015, 75, 617-625. [CrossRef]

38. Liao, T.W. Two interval type 2 fuzzy TOPSIS material selection methods. Mater. Des. 2015, 88, 1088-1099. [CrossRef]

39. Wang, C.N.; Nguyen, V.T.; Duong, D.H.; Thai, H.T.N. A Hybrid Fuzzy Analysis Network Process (FANP) and the Technique for Order of Preference by Similarity to Ideal Solution (TOPSIS) Approaches for Solid Waste to Energy Plant Location Selection in Vietnam. Appl. Sci. 2018, 8, 1100. [CrossRef]

40. Dubois, D. The role of fuzzy sets in decision sciences: Old techniques and new directions. Fuzzy Set. Syst. 2011, 184, 3-28. [CrossRef]

41. Moslem, S.; Ghorbanzadeh, O.; Blaschke, T.; Duleba, S. Analysing Stakeholder Consensus for a Sustainable Transport Development Decision by the Fuzzy AHP and Interval AHP. Sustainability 2019, 11, 3271. [CrossRef]

42. Wang, J.Q.; Wu, J.T.; Wang, J.; Zhang, H.Y.; Chen, X.H. Interval-valued hesitant fuzzy linguistic sets and their applications in multi-criteria decision-making problems. Inform. Sci. 2014, 288, 55-72. [CrossRef]

43. Law, M.; Bowie, G. Prediction of failure strain and burst pressure in high yield-to-tensile strength ratio linepipe. Int. J. Pres. Ves. Pip. 2007, 84, 487-492. [CrossRef]

44. Toutanji, H.; Dempsey, S. Stress modeling of pipelines strengthened with advanced composites materials. Thin. Wall. Struct. 2001, 39, 153-165. [CrossRef]

45. Reddy, G.P.; Gupta, N. Material selection for microelectronic heat sinks: An application of the Ashby approach. Mater. Des. 2010, 31, 113-117. [CrossRef] 
46. Jiang, G.M.; Sun, J.; Sharma, K.R.; Yuan, Z.G. Corrosion and odor management in sewer systems. Curr. Opin. Biotech. 2015, 33, 192-197. [CrossRef]

47. Zhang, Z.X.; Wang, G.X.; Massarotto, P.; Rudolph, V. Optimization of pipeline transport for $\mathrm{CO}_{2}$ sequestration. Energ. Convers. Manag. 2006, 47, 702-715. [CrossRef]

48. Davis, P.; Sullivan, E.; Marlow, D.; Marney, D. A selection framework for infrastructure condition monitoring technologies in water and wastewater networks. Expert Syst. Appl. 2013, 40, 1947-1958. [CrossRef]

49. Zhao, R.; Neighbour, G.; Deutz, P.; McGuire, M. Materials selection for cleaner production: An environmental evaluation approach. Mater. Des. 2012, 37, 429-434. [CrossRef]

50. Zhao, R.; Xi, B.; Liu, Y.; Su, J.; Liu, S. Economic potential of leachate evaporation by using landfill gas: A system dynamics approach. Resour. Conserv. Recycl. 2017, 124, 74-84. [CrossRef]

51. Bharati, S.K.; Singh, S.R. Transportation problem under interval-valued intuitionistic fuzzy environment. Int. J. Fuzzy Syst. 2018, 20, 1511-1522. [CrossRef]

52. Bobyr, M.V.; Milostnaya, N.A.; Kulabuhov, S.A. A method of defuzzification based on the approach of areas' ratio. Appl. Soft Comput. 2017, 59, 19-32. [CrossRef]

53. Chang, C.H.; Lin, J.J.; Lin, J.H.; Chiang, M.C. Domestic open-end equity mutual fund performance evaluation using extended TOPSIS method with different distance approaches. Expert Syst. Appl. 2010, 37, 4642-4649. [CrossRef]

54. Petit-Boix, A.; Sanjuan-Delmás, D.; Gasol, C.M.; Villalba, G.; Suárez-Ojeda, M.E.; Gabarrell, X.; Josa, A.; Rieradevall, J. Environmental Assessment of Sewer Construction in Small to Medium Sized Cities Using Life Cycle Assessment. Water Resour. Manag. 2014, 28, 979-997. [CrossRef]

55. Li, Y.R. Study on Scaling and Corrosion of HDPE Pipeline Material in Leachate Transportation. Master's Thesis, Southwest Jiaotong University, Chengdu, China, 2017.

56. Ashby, M.F.; Shercliff, H.; Cebon, D. Materials: Engineering, Science, Processing and Design; Butterworth-Heinemann: Oxford, UK, 2018.

57. de la Fuente, A.; Pons, O.; Josa, A.; Aguado, A. Multi-Criteria Decision Making in the sustainability assessment of sewerage pipe systems. J. Clean. Prod. 2016, 112, 4762-4770. [CrossRef]

(C) 2019 by the authors. Licensee MDPI, Basel, Switzerland. This article is an open access article distributed under the terms and conditions of the Creative Commons Attribution (CC BY) license (http://creativecommons.org/licenses/by/4.0/). 